\title{
Evaluation of antioxidant, antiangiogenic and antitumor properties of Anogeissus leiocarpus against colon cancer
}

\author{
Loiy Elsir Ahmed Hassan ${ }^{a, b^{*}}$, Foud Saleih R. Al-Suade ${ }^{a}$, Samah M.Fadul ${ }^{c}$, Amin Malik Shah Abdul Majid $^{a}$
}

\begin{abstract}
Anogeissus leiocarpus is a traditional medicinal plant, used to treat diarrhea, fever, coughs, rheumatism, leprosy, wounds and skin diseases and psoriasis. This study was aimed to investigate the antiangiogenic and cytotoxic effects of six extracts from Anogeissus leiocarpus (leaves and bark). Further, the tested biological activities were correlated with antioxidant capabilities, total phenolic and total flavonoid contents. In order to confirm the effect of the extract on motility of human endothelial cells, cell migration assay was conducted. In addition, VEGF suppressive effect of the extracts was assessed in endothelial cells. Finally, the antitumor effect of the leaves ethanolic extract was evaluated using in vivo human tumor xenograft model. A. leiocarpus extracts significantly inhibited the outgrowth of new vessels from rat aortic tissue explants by more than $50 \%$. Hexane extract of the stem bark and ethanolic leaves extract profoundly inhibited the sprouting of microvessels (by $89.56 \%$ and $87.12 \%$ respectively) in rat aortic ring assay. The ethanol extract of the leaves inhibited HUVEC migration by 87.57 and $65.23 \%$ after 18 hours at $80 \mu \mathrm{g} / \mathrm{ml}$ and $40 \mu \mathrm{g} / \mathrm{ml}$ concentrations respectively; it also demonstrated significant inhibition of VEGF levels $(45.32 \%$ and $30.52 \%$ respectively) in treated endothelial cells. The ethanol extract of the leaves showed remarkable DPPH scavenging effect with $I_{50}=29.87 \mu \mathrm{g} / \mathrm{ml}$.
\end{abstract}

\section{Significance | Anogeissus leiocarpus curbs tumor angiogenesis and tumor growth}

*Correspondence: a. EMAN Research and Testing Laboratory, School of Pharmaceutical Sciences, Universiti Sains Malaysia, Penang, Malaysia. b. Department of Botany, Faculty of Sciences\& Technology, Omdurman Islamic University, P.O. Box. 383. E-mail: loiy.ahmed23@gmail.com

Edited by Md Asaduzzaman Shishir, Centre for Advanced Research in Sciences, University of Dhaka, Dhaka-1000, Bangladesh., and accepted by the Editorial Board July 26, 2018 (received for review May 5, 2018)
Furthermore, it displayed higher levels of total phenolics and flavonoids compared to other extracts. Finally the ethanol extract of the leaves exhibited potent anti-tumorigenic effect in anthymic mice with $\Delta T / \Delta \mathrm{C}$ $=2.97$ and $7.54 \%$ at doses 400 and $200 \mathrm{mg} / \mathrm{kg}$, respectively. These results may provide novel guidelines towards improved strategies using Anogeissus leiocarpus extracts based on the suppression of angiogenesis to curb tumors growth. The plant can be used as promising candidate for anti-neoplasic drug development.

Keywords: antiangiogic, antitumor, colon cancer, Anogeissus leiocarpus, antioxidant, total phenolic and flavonoid contents, ring assay, VEGF, cell migration

Abbreviations: VEGF, vascular endothelial growth factor, HUVEC:Human umbilical vein endothelial cells, MTT: 3-(4,5-dimethylthiazol-2-yl)-2,5-diphenyltetrazolium bromide, LEE: Leaves Ethanolic Extract of A. leicarpus

\section{Introduction}

Cancer is a dreadful disease that affects millions of people around the globe. Its complexity requires different strategies to reduce its morbidity and mortality that include cancer prevention, cancer therapy and impeding cancer recurrence. To achieve more success in treatment and chemoprevention, several approaches need to be applied targeting neoplastic cells and tumor microenvironment. These could be by counteracting toxins and chemical carcinogens, blocking reactive species, inducing apoptosis in cancer cells, inhibiting tumor angiogenesis and reducing nutrients supply to the tumor (De Flora \& Ferguson, 2005).

Angiogenesis is a term used to describe sprouting of new blood vessels from the pre-existing vasculature. It occurs normally during embryogenesis and in adulthood during wound healing

\section{Author Affiliation:}

a EMAN Research and Testing Laboratory, School of Pharmaceutical Sciences, Universiti Sains Malaysia, Penang, Malaysia.

${ }^{b}$ Department of Botany, Faculty of Sciences\& Technology, Omdurman Islamic University, P.O. Box. 383.

${ }^{\mathrm{C}}$ School ofHeath Sciences, Ahfad Univeristy for Women,P.O.Box167, Omdurman, Sudan

Please cite this article:

Hassan LEA, AI-Suede FS, Fadul SM, Abdul Majid AMS. (2018). Evaluation of antioxidant antiangiogenic and antitumor properties of Anogeissus leiocarpus against colon cancer. Angiotherapy, 1(2), pages 56-66.

doi: 10.25163/angiotherapy. 1200021526100818 
and uterus functions (Carmeliet, 2005; Folkman \& Klagsbrun, 1987). Nevertheless, pathologic angiogenesis is involved in some diseases such as cancer, diabetic retinopathy; chronic inflammation, atherosclerosis and psoriasis (Kim, West, \& Byzova, 2013; Kumamoto, Nakashima, \& Sueishi, 1995). Cancers that lack angiogenesis remain dormant while aggressive growth follows the acquisition of a blood supply, so tumor angiogenesis is a key event that supply tumor with nutrients and enhance cancer metastases (Sagar, Yance, \& Wong, 2006). Anti-angiogenic approach to prevent and treat cancer represents a priority area in investigative tumor biology.

In the treatment of some types of cancer, botanicals have long been used traditionally and often less associated with the side effects of modern chemotherapy. Medicinal herbs have increasingly become important as therapeutic agents and a source of chemical diversity in drug discovery (Subbaraju \& Trimurtulu, 2004).

Anogeissus leiocarpus has a large ecological distribution, ranging from the borders of the Savanna up to the humid tropical forests region (Hennenberg et.al ; Porembski, 2005). It is used traditionally for the treatment of helminthiasis, trypanosomiasis, malaria and dysenteric syndrome. Also it used for the treatment of diarrhea, fever, coughs, rheumatism, leprosy, wounds and skin diseases and psoriasis (Okpekon et al., 2004; Singh et al., 2016). Furthermore Anogeissus leiocarpus has also been shown to have antimicrobial activities, potent in vitro antioxidant and organ protective properties in vivo (Konaté et al., 2011; Ottu, Atawodi, \& Onyike, 2013). Phytochemical studies have shown that $A$. leocarpus leaves are rich in alkaloids, flavonoids and phenolic, and saponins compounds (Theresa Ibibia, Oghenerobor Benjamin, \& Stephen Olugbemiga, 2016), the presences of these biochemical components suggest their potential use in cancer treatment.

Free radicals and oxidative agents implicated in the pathogenesis of diseases such as cancer, diabetes, hypertension, cardiac disorder, arteriosclerosis ect. Free radicals are capable of oxidatively damaging lipids and proteins as well as DNA integrity (Phaniendra, Jestadi, \& Periyasamy, 2015; Therond, 2006). Natural products containing polyphenols have been widely studied and used as a source of antioxidants to scavenge excessive free radicals in various disease models (Russell \& Duthie, 2011; Shahidi \& Naczk, 1995). Antioxidants have been reported to have potent antiangiogenic properties, these compounds work by regulating angiogenesis modulators such as vascular endothelial growth factor (VEGF) (Papiewska-Pająk, et al; Boncela, 2017) or by changing the redox microenvironment of tumor vasculature (Saggar, Yu, Tan, \& Tannock, 2013), thus potentially can modulate the process of angiogenesis. Antiangiogenic activity evaluation of the extracts may reveal antitumor and chempoprevention potential of the plant due to its inhibitory effect of blood vessel formation (Hassan et al., 2016). Given its known antioxidant value, this study explores for the first time the potential antiangiogenic and antitumor properties of extracts from Anogeissus leiocarpus.

\section{Materials and Methods}

Plant material was collected in March 2016 from Elgadarif State -Sudan. The taxonomic identification of this plant was carried out at The Medicinal and Aromatic Plants Research Institute, National Center for Research, a voucher specimen (Ref. No. MAPRI- 380774/2016) was deposited at the herbarium of the institute.

\section{Preparation of extracts}

Collected plant materials were oven dried at $45^{\circ} \mathrm{C}$. The plant material was successively extracted with $n$-hexane, ethanol and water. N-hexane extract was prepared by adding $300 \mathrm{ml} \mathrm{n}$-hexane to $50 \mathrm{~g}$ of the pulverized plant material, extraction was carried out at $40^{\circ} \mathrm{C}$ with intermittent shaking. The extract was filtered and concentrated at $45^{\circ} \mathrm{C}$ under vacuum by rotary evaporator (Buchi, USA) and further dried overnight at $45^{\circ} \mathrm{C}$. The plant residues were then re-extracted with ethanol and water each for further $24 \mathrm{~h}$ and were processed as mentioned above. Stock solutions of the extract were prepared at $10 \mathrm{mg} / \mathrm{ml}$ in $100 \%$ dimethyl sulfoxide (DMSO). The stock solutions as well as DMSO (vehicle) were diluted with cell culture medium, so the highest DMSO concentration exposed to the cells and explanted tissue was $0.1 \% \mathrm{v} / \mathrm{v}$.

\section{Experimental animals}

The 12-14 weeks old Sprague Dawley male rats were obtained from animal house facility of USM. The rats were kept in well ventilated cages at $12 \mathrm{~h}$ light with food and water in animal transient house (School of Pharmaceutical Sciences, USM) for one week prior to the experiment. Athymic NCR nu/nu nude mice were obtained from Taconic Farms Inc., USA. The mice of the same gender were housed in specific pathogen-free (SPF) cages supplied with high efficiency particulate air (HEPA) filters. Free access to autoclaved food and water was provided and the autoclaved bedding was changed twice weekly. The procedures were approved by the USM Animal Ethics Committee with a reference number USM/Animal Ethic approval/2012/ (81) (475)

Cell lines and cell culture. Human Umbilical Vein Endothelial Cell line HUVEC; was purchased from ScienCell, USA. Human colorectal carcinoma cell line HCT-116; human hormone sensitive and invasive breast cancer line MCF-7 and human fibroblast normal colon cell line CCD-18 Co. Cell culture reagents were purchased from Gibco, USA; RPMI 1640 medium; Dulbecco's Modified Eagle Medium (DMEM); M199 medium; Foetal Bovine Serum (FBS), Penicillin/ Streptomycin (PS) solution. The following reagents; were purchased from Sigma, Germany; MTT reagents, Human Insulin, Suramin, Amphotericin B, Dimethyl 
sulfoxide (DMSO, Aprotinin, 6-Aminocaproic acid, L-glutamine, Thrombin and Gentamicin. Fibrinogen was purchased from Calbiochem, USA. Endothelial Cell Medium (ECM) supplied with endothelial cell growth supplements (ECGS) was obtained from ScienCell, USA. All cells were maintained at $37^{\circ} \mathrm{C}, 5 \% \mathrm{CO}_{2}$ and humidity in $\mathrm{CO}_{2}$ incubator (Binder, Germany). HUVEC was propagated in ECM supplemented with 5\% FBS, 1\% PS and 1\% ECG. HCT-116 was propagated in RPMI-1640 supplemented with $10 \%$ FBS, and $1 \%$ PS. MCF-7 was propagated in DMEM supplemented with $10 \%$ FBS and 1\% PS. work was done in sterile conditions using Class II biosafety cabinet (ESCO, USA).

\section{Rat aorta ring assay}

The assay was performed according to standard protocol with minor modifications (Brown et al. 1996; Blacher, et al., 2011; Hassan et al., 2014).

Preparation of aortic rings. The animals were humanely sacrificed via cervical dislocation under anesthesia with $\mathrm{CO}_{2}$ in close chamber. A midline was made into the abdominal and thoracic cavities including splitting of the sternum. Thoracic aortas were excised, rinsed with serum free media, fibroadipose tissue removed and were cross sectioned into thin rings of about $1 \mathrm{~mm}$ thickness.

Preparation of the tissue culture plates. Medium for the lower layer was prepared by adding fibrinogen and aprotonin at 3 $\mathrm{mg} / \mathrm{ml}$ and $5 \mathrm{mg} / \mathrm{ml}$, respectively to M199 basal medium. The $300 \mu \mathrm{l}$ of this mixture was loaded in each well of 48 -well plate. Aortic ring sections are then place in each well. $10 \mu \mathrm{l}$ of thrombin; prepared at $50 \mathrm{NIH} \mathrm{U} \mathrm{mL} \mathrm{mL}^{-1}$ in $0.5 \mathrm{M} \mathrm{NaCl}$; bovine serum albumin; was added to each well and was allowed to solidify at $37^{\circ} \mathrm{C}$ in $5 \%$ $\mathrm{CO}_{2}$ for $60-90 \mathrm{~min}$. The top layer medium was prepared by adding the following to M199 basal medium: FBS at 20\% v/v, L-glutamine at $1 \%$ aminocaproic acid at $0.1 \%$ amphotericin $\mathrm{B}$ at $1 \%$ and gentamicin at $0.6 \%$. The extracts were added to top layer medium at $100 \mu \mathrm{g} / \mathrm{ml}$ and were incubated at $37^{\circ} \mathrm{C}$ in $5 \% \mathrm{CO}_{2}$ in a humidified incubator. On day four the top layer medium was changed with fresh medium prepared as previously mentioned with the plant extracts added at $100 \mu \mathrm{g} / \mathrm{ml}$. DMSO was used as a negative control.

Quantification of the blood vessels outgrowth. The magnitude of blood vessels outgrowth was quantified according to the technique developed by Nicosia et al. (1997) (Staton et al., 2004). Briefly, the distance of blood vessels outgrowing from the primary tissue ex-plant was measured on day five under the $4 \mathrm{x}$ magnification power of inverted light microscope supplied with Lecia Quin computerized imaging system. The growth distance of at least twenty blood vessels per ring was measured; blood vessels were selected at regular intervals around the rings to reduce the bias. The experiment was performed in triplicates each replicate containing six rings and the results were presented as a mean percent inhibition to the negative control $(n= \pm 5)$ Standard Deviation (SD).

\section{Cytotoxicity assay}

The MTT cytotoxicity assay was performed according to the method developed by Mosmann (1983) with minor modifications (Hassan et al., 2014; Mosmann, 1983). Cells were seeded at $1.5 \times 104$ cells in each well of 96 -well plate in $100 \mu \mathrm{l}$ of fresh culture medium and were allowed to attach for overnight. The stock solutions of extracts were diluted in cell culture medium to obtain $100 \mathrm{mg} / \mathrm{ml}$ and $100 \mu \mathrm{l}$ was added to each well. After $48 \mathrm{~h}$ of the treatment the medium was aspirated and the cells were exposed to MTT solution prepared at $5 \mathrm{mg} / \mathrm{ml}$ in sterile PBS was added to each well at $10 \% \mathrm{v} / \mathrm{v}$ in respective medium and was incubated at $37^{\circ} \mathrm{C}$ in $5 \% \mathrm{CO}_{2}$ for $3 \mathrm{~h}$. The water insoluble formazan salts was solubilized with $200 \mu \mathrm{LSMO} /$ well. Absorbance was measured by i-control $^{\text {tw }}$ - Microplate Reader Software TECAN Group Ltd., Switzerland) at primary wave length of $570 \mathrm{~nm}$ and reference wavelength of $620 \mathrm{~nm}$. Each plate contained the samples, negative control and blank. DMSO at less than $1 \% \mathrm{v} / \mathrm{v}$ was used as a negative control. The assay was performed in quadricates the results are presented as a mean percent inhibition to the negative control \pm SD.

\section{Determination of total phenols}

Total phenols in tested extracts were determined by a colorimetric method as described by Chirinos et al. (Chirinos, Pedreschi, Rogez, Larondelle, \& Campos, 2013). $100 \mu \mathrm{l}$ of extracts $(1 \mathrm{mg} / \mathrm{ml}$ in methanol) was added to $750 \mu \mathrm{l} 1: 10$ diluted (in dd. $\mathrm{H}_{2} \mathrm{O}$ ) Folin-Ciocalteau phenol reagent. After 5 min incubation in the dark at room temperature, $750 \mu \mathrm{l}$ sodium bicarbonate solution (60 $\mathrm{g} / \mathrm{l}$ ) was added and incubated at $30^{\circ} \mathrm{C}$ in the dark for $90 \mathrm{~min}$. Afterwards absorbance was measured at $725 \mathrm{~nm}$. Gallic acid was used $(5-80 \mu \mathrm{g})$ to construct the standard calibration curve. The results were expressed as gallic acid equivalents per $100 \mathrm{mg}$ of extract (mg GAE/100mg).

\section{Determination of total Flavonoids}

The total flavonoid contents in studied extracts were determined using aluminum chloride colorimetric method with quercetin as standard (Mammen \& Daniel, 2012). A solution of 6 $\mathrm{mg} / \mathrm{ml}$ of A. leiocarpus extracts in $80 \%$ methanol and different concentrations of quercetin $(0.007,0.015,0.0313,0.0625$, $0.125,0.25,0.5$, and $1 \mathrm{mg} / \mathrm{ml}$ in $80 \%$ methanol) were prepared. Briefly, $500 \mu \mathrm{l}$ of plant extracts and each concentration of quercetin (Sigma Aldrich, Germany) were pippetted in respective test tubes followed by $0.1 \mathrm{ml}$ of $10 \%$ (w/v) aluminum chloride (R \& M Chemicals, UK), $0.1 \mathrm{ml}$ of $1 \mathrm{M}$ potassium acetate (Merck, Germany), $1.5 \mathrm{ml}$ of methanol and $2.8 \mathrm{ml}$ of distilled water. The test tubes were thoroughly mixed and after incubating at room temperature $\left(24\right.$ to $26^{\circ} \mathrm{C}$ ) for $30 \mathrm{~min}$, the absorbance of the reaction mixture was measured at $415 \mathrm{~nm}$ with Microplate Reader 
Software (TECAN Group Ltd., Switzerland) against blank. The amount of $10 \%(\mathrm{w} / \mathrm{v})$ aluminum chloride was substituted by the same amount of distilled water in a blank. The concentration of total flavonoid contents of the extracts were determined using a standard curve with quercetin (Sigma-Aldrich Chemie, Steinheim, Germany) (0 to $50 \mathrm{mg} / \mathrm{ml}$ ) as the standard. The data were presented as mean $(n=3)$. Standard Deviation (SD)

\section{DPPH scavenging effect}

DPPH scavenging effect of extracts was investigated as described by Sharma and Bhat (2009) (Sharma \& Bhat, 2009). Briefly, stock solution of DPPH was prepared in methanol at $200 \mu \mathrm{M}$, and serial dilution of extracts was prepared in methanol to obtain $(200,100$, $50,25$ and $12.5 \mu \mathrm{g} / \mathrm{ml})$. DPPH reagent was added at final concentration of $50 \mu \mathrm{M}$ and incubated at $30^{\circ} \mathrm{C}$ in the dark for $30 \mathrm{~min}$. Consequently, absorbance was measured at $517 \mathrm{~nm}$ and $\mathrm{DPPH}$ scavenging activity was calculated using the formula (1-(absorbance of samples-blank)/ (absorbance of negative control blank $)) \times 100 \%$. Median inhibitory concentration $\left(\mathrm{IC}_{50} \mathrm{~s}\right)$ were calculated from the dose response curves $(n=3)$. Gallic acid was used as a positive control and the solvent (methanol) was used as a negative control.

\section{Migration Assay}

The assay was carried out as described previously (Hassan et al., 2017; Liang, Park, \& Guan, 2007). In brief, HUVECs were seeded in 6 well plates till the formation of a confluent monolayer after which a wound was created using $200 \mu$ micropipette tip. The detached cells were removed by washing with PBS and the plates were treated with ethanol extract of A. leiocarpus. The wounds were photo-graphed after 12 and $18 \mathrm{~h}$, and the width of the cell-free wounds was measured using an inverted light microscope supplied with Leica Quin computerized imaging system. Ten fields per well were photographed and minimum of 30 readings per field were taken. The results are presented as mean percentage of migration inhibition compared to control $\pm \mathrm{SD}$, (n $=3$ ).

\section{Determination of VEGF levels}

Concentration of human VEGF in HUVEC cells lysates was determined by human VEGF ELISA kit (China) according to manufacturer's instructions. The kit consists of anti-human VEGF-1 mouse IgG monoclonal antibody and a horseradish peroxidase conjugated secondary antibody and recombinant human VEGF 165 as a standard. HUVEC cells were seeded in 6 -well plates at $1 \times 106$ in $3 \mathrm{~mL}$ of ECM medium. After overnight attachment, the cells were treated for $6 \mathrm{~h}$ with A. leiocarpus ethanol and water extracts of the leaves in addition to water extract of the bark at 50 and $100 \mu \mathrm{g} / \mathrm{ml}$ (extracts those showed high inhibition of blood vessels). Calibration curve of VEGF standard was prepared simultaneously with the samples, and concentration of VEGF-1 in cell lysates was determined by apply- ing the linear regression equation, $\left(y=0.039 x+0.3121, R^{2}=0.986\right)$.

\section{In vivo antitumor study}

HCT-116 human colorectal carcinoma cells was selected as a model of colon cancer (Baghel, Shrivastava, RS Baghel, \& Rajput, 2012). The cells were propagated in RPMI 1640 medium with $10 \%$ FBS and 1\% PS solution. $80 \%$ confluent HCT-116 cells cultures in T75 flasks were trypsinized and re-suspended in $10 \mathrm{ml}$ fresh medium, the cells were collected by centrifugation at 1000 rpm for 5 minutes and washed with a sterile PBS. The nude mice with aged $5-7$ weeks were injected subcutaneously in the right flank with $5 \times 106$ cells in $200 \mu$ culture medium using $1 \mathrm{ml}$ insulin syringe (27 G needle).

After one week of tumor initiation, animals were divided randomly into four groups of 6 animals each. Group 1 received 0.2 $\mathrm{ml}$ distilled water (control), and Groups 2, 3 and 4 received oral treatments with 400, 200 and $100 \mathrm{mg} / \mathrm{kg}$ bodyweight of ethanol extract of A. leiocarpus, respectively. The tumor size and body weight were recorded before starting the treatment and at weekly basis. Treatment of animals was performed orally by oral gavages (wt/wt) once a day for a period of 5 weeks. The tumor dimensions were measured by a caliber in 2 angles, length and width as well as depth (Tomayko \& Reynolds, 1989). The tumor size was calculated by applying the formula: Tumor volume $(\mathrm{mm} 2)=(\mathrm{W}+\mathrm{L}) / 2) \wedge 3)$ $\times 2$ Where $\mathrm{W}$ is the width and $\mathrm{L}$ is the length. Also following value was calculated $: \% \Delta \mathrm{T} / \Delta \mathrm{C}$, where, $\Delta \mathrm{T}=\mathrm{T}-\Delta 0$ and $\Delta \mathrm{C}=\mathrm{C}-\Delta 0$ ( $\Delta 0$ is the average tumor volume at the beginning of the treatment, $\mathrm{T}$ and $\mathrm{C}$ are the tumor volumes at a specified day for treated and control groups, respectively). Generally, the $\Delta \mathrm{T} / \Delta \mathrm{C}$ value in percent is used as an indication of antitumor effectiveness, and a value of $\Delta \mathrm{T} / \Delta \mathrm{C} \leq 42 \%$ is considered as significant antitumor activity by the Division of Cancer Treatment, NCI, NIH (Corbett et al., 2004).

\section{Haematoxylin and Eosin (HEE) histology staining}

The excised tumors were cut into sections of about $0.5 \mathrm{~cm}^{2}$ sizes and fixed in $10 \%$ formalin for $48 \mathrm{~h}$, embedded in paraffin wax (Leica EG1160, Germany) and the blocks trimmed and sectioned to about $5 \times 5 \times 4 \mu \mathrm{m}$ size using a microtome (Leica RM2155). The tissue sections were mounted on glass slides using a hot plate (Leica HI1220, Germany) and subsequently treated with alcohol. The processed tissues were rinsed with tap water and finally stained with the Harris's haematoxylin and eosin (H \& E) (Luna \& Armed Forces Institute of, 1968) and examined under an inverted light microscope (EVOS) at $4 \mathrm{x}$ magnification.

\section{Results}

In this study we screened six extracts obtained from the leaves and stem bark of Anogeissus leiocarpus using three solvents (n-hexane, ethanol and water). Sequencing extraction of leaves and bark of Anogeissus leiocarpus reveals that all leaves extracts exhibited higher yield compared with stem bark extracts. The 
Table 1 | The extraction results of Anogeissus leiocarpus, the yield presented as wt/wt percent.

\begin{tabular}{llll}
\hline Used part & Solvent & Texture & Yield\% \\
\hline Bark & n-hexane & gummy & $0.1948 \%$ \\
& Ethanol & sticky & $4.184 \%$ \\
& Water & powder & $6.81 \%$ \\
Leaves & n-hexane & gummy & $5.06 \%$ \\
& Ethanol & solid & $12.39 \%$ \\
& Water & powder & $11.85 \%$ \\
\hline
\end{tabular}

Table 2 | The antiangiogenic effect of Anogeissus leiocarpus extracts on rat aortic ring assay.

\begin{tabular}{lll}
\hline Plant part & Solvent & Inhibition\% \\
\hline Bark & n-hexane & $89.56 \%$ \\
& Ethanol & $66.34 \%$ \\
& Water & $79.32 \%$ \\
& n-hexane & $29.10 \%$ \\
\hline Leaves & Ethanol & $87.12 \%$ \\
& Water & $77.66 \%$ \\
\hline Suramin & & $91.3 \%$ \\
\hline
\end{tabular}

extract of the leaves proofed to have the superior yield $12.39 \%$ $(\mathrm{w} / \mathrm{w})$ followed by water extract of the same organ $11.85 \%(\mathrm{w} / \mathrm{w})$ and water extract of the bark $6.81 \%(\mathrm{w} / \mathrm{w})$. The hexane extract of the bark showed the lowest yield $0.195 \%$ (w/w) Table 1 .

\section{Antiangiogenic activity}

The ex vivo rat aortic ring assay mimics the physiologic in vivo situation, since endothelial cells are in a quiescent state, in a natural histological environment. Rat Aorta Ring Assay (RARA) was used as platform to evaluate the antiangiogenic activity of Anogeissus leiocarpus. The $\mathrm{n}$-hexane extract of the bark and ethanol extract of the leaves exerted the highest antiangiogenic activity i.e. $89.56 \%$ and $87.12 \%$ respectively, while the standard drug surman inhibited the growth of new vessels by $91.3 \%$. The water extracts of two parts showed relatively high activity (77.66\% for the leaves and $79.32 \%$ for the bark). Plant extracts with more than $50 \%$ inhibition of the blood vessels outgrowth were considered significant, so all the extracts of Anogeissus leiocarpus showed significant antiangiogenic activity except the n-hexane extract of leaves (29.10\%). Table 2.

In this ex-vivo rat aorta ring assay, among six extracts screened, ethanol extract of the leaves and hexane extract of bark profoundly inhibited the sprouting of new blood vessels from explanted tissue, therefore it was subjected for further mechanistic studies on HUVEC human endothelial cells and evaluated for antitumor efficacy due to its ability to inhibit the growth of new blood vessels and to its safety profile.

\section{Cytotoxicity}

In vitro cytotoxicity test on human normal and cancer-derived cells is essential for determining the real antiangiogenic effect from inhibition of vasculature due to toxicity effect thus was also done in the current study.

The MTT assay was used to screen cytotoxic activity of six extracts of Anogeissus leiocarpus. Two cancer cell lines were used for general screening namely colon cancer cell line (HCT-116) and breast cancer cell line (MCF-7). Two normal cell lines (HUVECs and CCD-18 Co) were also tested on for comparison. The cells were treated with extracts at $100 \mu \mathrm{g} / \mathrm{ml}$ for $48 \mathrm{~h}$, the assay was performed in quadricates and the results were presented as a mean percent inhibition to the negative control \pm SD. Table 3 shows the cytotoxicity result by MTT assay. The n-hexane of the bark found to be selectively cytotoxic against HUVEC cell line with inhibitory effect $76.87 \%$ it was also moderately cytotoxic against HCT-116 colon cancer cell line, as well as ethanol extract of the same organ with inhibition $61.24 \%$ and $58.25 \%$ respectively. The rest of the extracts were non-toxic on all tested cell lines.

\section{Antioxidant activity}

In the current study, antioxidant assays were carried out on six extracts to correlate the antiangiogenic effect and antioxidant activity of each extract. Three methods were used to assess the antioxidant activity of different extracts that is $\mathrm{DPPH}$ radical scavenging activity, total phenolic and total flavonoid contents.

Ethanol extract of the leaves and the bark exhibited very high free radical scavenging effect with $\mathrm{IC}_{50}=29.87 \mu \mathrm{g} / \mathrm{ml}$ and $43.34 \mu \mathrm{g} / \mathrm{ml}$ respectively in DPPH scavenging assay. Hexane extract of the leaves showed the lowest antioxidant effect (with $\mathrm{IC}_{50}=193.05$ $\mu \mathrm{g} / \mathrm{ml})$ followed by the water extract of the bark $(111.43 \mu \mathrm{g} / \mathrm{ml})$.

The amount of phenolic compounds present in each extract were determined from linear regression equation of calibration curve, [y $\left.=0.0034+0.0144\left(\mathrm{R}^{2}=0.9976\right)\right]$ and expressed as Gallic acid equivalent in $\mathrm{mg} / \mathrm{ml}$ of extracts, the results is presented in table 3 . Total phenols content was in the range of $14.85 \pm 0.02$ and 497.74 $\pm 0.01 \mathrm{GAE}$. The lowest phenolic content was exhibited by n-hexane of the leaves. While water extracts of two parts (bark and leaves showed the highest phenol content $497.74 \pm 0.01$ and $448.45 \pm 0.02$ GAE respectively, followed by the ethanol extract of the leaves $300.40 \pm 0.03$ GAE. From these results the antiagiogenic effect of extracts corresponds with their phenolic contents. In this study total amount of Flavonoids content in each extract were determined from the linear regression equation of calibration curve, $\left[\mathrm{y}=0.0032+0.0669 \quad\left(\mathrm{R}^{2}=0.986\right)\right]$ (as described in the method) and expressed as quercetin equivalents in $6 \mathrm{mg} / \mathrm{ml}$ of extracts (Table 3 ). The highest amount of flavonoids scored by water and ethanol extracts of the leaves $110.350 \pm 0.0$ and $78.642 \pm 0.01 \mathrm{mg} / \mathrm{g}$ respectively, while ethanol of the bark showed the lowest contents of flavonoids $(8.317 \pm 0.00 \mathrm{mg} / \mathrm{g})$. From the results it is evident that extracts with high total phenols content have high antioxidant activity, and vice versa. 

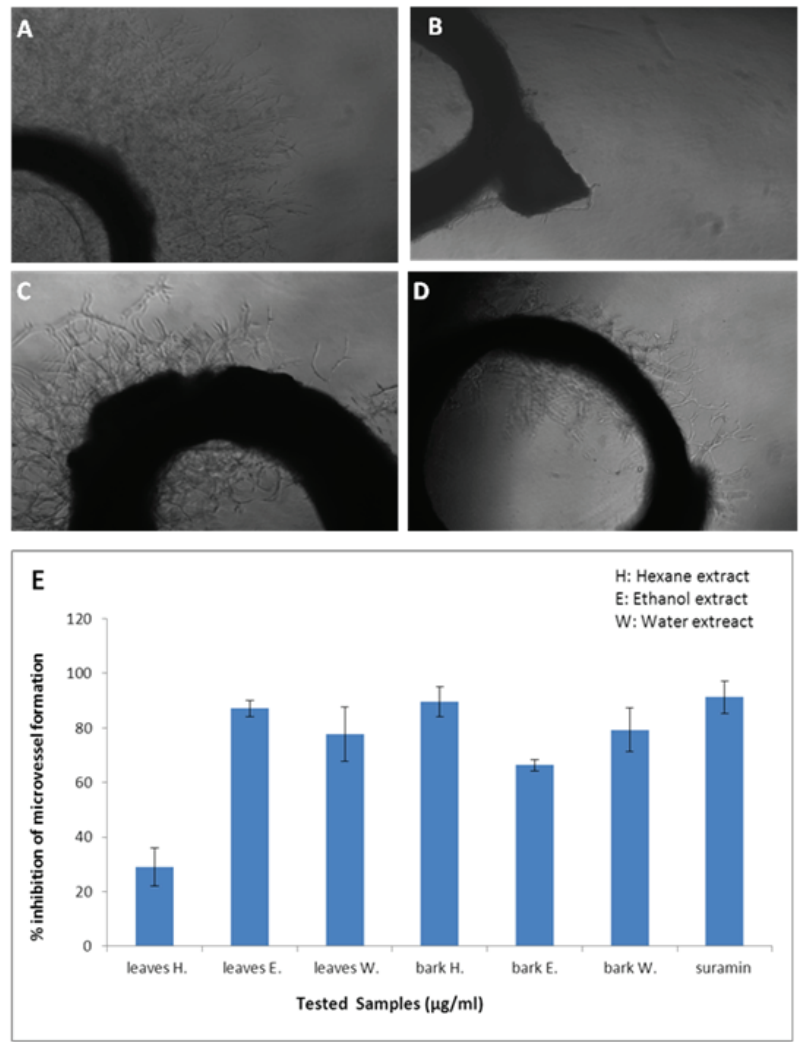

Table 3 | The Cytotoxic effect of Anogeissus leiocarpus extracts on cancer and normal cell lines

\begin{tabular}{cccccc}
\hline Plant part & Solvent used & \multicolumn{4}{c}{ Cells inhibition \% } \\
\cline { 3 - 6 } Bark & HCT-116 & MCF-7 & CCD-18Co & HUVECs \\
& n-Hexane & 61.24 & 34.07 & 29.417 & 76.87 \\
& Ethanol & 58.25 & 19.58 & 13.67 & 33.47 \\
\multirow{2}{*}{ Leaves } & Water & 1.73 & 19.65 & 9.529 & 0.88 \\
& n-Hexane & 3.08 & 9.60 & 0.86 & 3.65 \\
& Ethanol & 1.84 & 13.63 & 1.329 & 5.80 \\
& Water & 1.19 & 14.89 & 18.55 & 1.14 \\
\hline
\end{tabular}

Table 4 Phenolic and Flavonoids contents and DPPH scavenging of Anogeissus leiocarpus.

\begin{tabular}{ccccc}
\hline Part used & Solvent & DPPH $\left(\mathrm{IC} \mathrm{C}_{5}\right) \mu \mathrm{g} / \mathrm{mL}$ & Total flavonoids $(\mathrm{mg} / \mathrm{g})$ & Total phenolics $(\mathrm{mg} / \mathrm{g})$ \\
\hline Bark & $\mathrm{n}$-Hexane & 119.55 & $44.950 \pm 0.01$ & $85.22 \pm 0.01$ \\
& Ethanol & 43.34 & $8.317 \pm 0.00$ & $96.56 \pm 0.02$ \\
& Water & 111.43 & $65.150 \pm 0.00$ & $497.74 \pm 0.01$ \\
\hline \multirow{2}{*}{ Leaves } & $\mathrm{n}$-Hexane & 193.05 & $28.567 \pm 0.01$ & $14.85 \pm 0.02$ \\
& Ethanol & 29.87 & $78.642 \pm 0.01$ & $300.40 \pm 0.03$ \\
& Water & 65.65 & $110.350 \pm 0.0$ & $448.45 \pm 0.02$ \\
\hline
\end{tabular}

In this study, extracts with high DPPH radical scavenging activity, total phenolic and total flavonoid content i.e. ethanol and water extracts, showed high level of antiangiogenic activity. $\mathrm{N}$-Hexane extract of the leaves having the lowest total phenolic and flavonoid level exhibited the lowest antiangiogenic activity. Results obtained from this study clearly showed that there is a good accordance with antioxidant activity and antiangiogenic effect of extracts, since the polyphenols and flavonoids inhibit the initiation and progression of angiogenesis (Walter et al., 2009). Therefore, botanical may play an important role in halting angiogenesis and tumor progression.

Effect of Anogeissus leiocarpus extracts on VEGF expression. To investigate the mechanism of action for antiangiogenic property of A. leocarpus, we studied the effect of active extracts on expression of VEGF165 on HUVECs. It significantly reduced
Figure 1 Effect of different A. leiocarpus extracts on new vessels formation in ex vivo rat aorta ring assay, (A) explants treated with $1 \%$ DMSO (vehicle), (B) tissue treated with ethanol extract of the leaves, (C) bark ethanolic extract, (D) explant treated with Suramin as a positive control. (Images were taken under an inverted phase-contrast microscope at 4X). (E) Graphical representation of the inhibitory effect tested extracts on blood vessel growth in rat aortic rings at concentrations of $100 \mu$ $\mathrm{g} / \mathrm{mL}$. All values are represented as the mean $\pm \operatorname{SD}(n=10)$, and $\star * *$ indicates significant differences of $p<0.001$ compared with the control-treated group (DMSO)

the level of VEGF compared to untreated cells $(\mathrm{P}<0.01)$. At concentration 50 and $100 \mu \mathrm{g} / \mathrm{ml}$ ethanol extract inhibited the VEGF by $30.32 \%$ and $44.05 \%$ respectively, the VEGF concentration in HUVEC cell lysate treated with ethanol extract of the leaves at $50 \mu \mathrm{g} / \mathrm{ml}$ was $0.990 \mathrm{pg} / \mathrm{ml}$ and at $100 \mu \mathrm{g} / \mathrm{ml}$ was $0.86 \mathrm{pg}$, while it was $1.953 \mathrm{pg} / \mathrm{ml}$ in untreated cells (Figure 2A). Water extracts of leaves and stem bark also significantly inhibited VEGF expression at high concentration by $40.15 \%$ and $39.69 \%$ respectively (Figure 2B). The results achieved in this study suggests that A. leiocarpus leaves ethanol extract (LEE) inhibited angiogenesis by curtailing secretion of the main angiogenesis growth factor (VEGF)

\section{Cell migration assay}

The effect of ethanol extract on HUVECs cell migration was assessed using wound healing assay (figure $3 \mathrm{~A}$ ). It substantially reduced endothelial cell (HUVECs) motility, at concentration $40 \mu$ $\mathrm{g} / \mathrm{ml}$ the extract inhibited migration of cell by $51.7 \pm 2.11 \%$ and $65.23 \pm 2.6 \%$ after 12 and $18 \mathrm{~h}$ incubation period, respectively $(\mathrm{P}<$ 0.05). At $80 \mu \mathrm{g} / \mathrm{ml}$ it inhibited HUVECs migration by $74.6 \pm 1.37 \%$ and $87.1 \pm 2.7 \%$ after $12 \mathrm{~h}$ and $18 \mathrm{~h}$ treatment, respectively $(\mathrm{P}<$ 0.001) (Figure 3B).

VEGF is the most important mitogenic and survival factor for vascular endothelial cells; many chemopreventive agents have been shown to inhibit VEGF mediated signaling and biological effects in endothelial cells (Albrecht et al., 2010; Rini \& Small, 2005). As discussed earlier the ethanol extract of the leaves profoundly inhibited the expression of VEGF in HUVECs endothelial cells suggesting that it inhibits cell endothelial cell migration via inhibition of VEGF expression.

\section{Antitumor activity of Anogeissus leiocarpus leaves extract}

Tumor-bearing NCR NuNu nude mice were orally administered with leaves ethanolic extract once a day for 35 days. The results showed that animals treated with (LEE) showed dose dependent reduction in tumor size, figure 4.B illustrates the tumor growth in respective tested groups. A significant $\Delta \mathrm{T} / \Delta \mathrm{C}=7.54 \%$ antitumor activity of (LEE) (at a dose of $200 \mathrm{mg} / \mathrm{kg}$ ) on 5 week post-cell inoculation day was observed. At a dose of $400 \mathrm{mg} / \mathrm{kg}$ it showed profound activity $(\Delta \mathrm{T} / \Delta \mathrm{C}=2.97 \%, \mathrm{P}<0.001)$. There was no toxicity effect of (LEE) on body weight of treated animals (Figure 4.C). The histological study of the excised tumors showed fewer blood vessels in tumors and some signs of necrosis of treated 


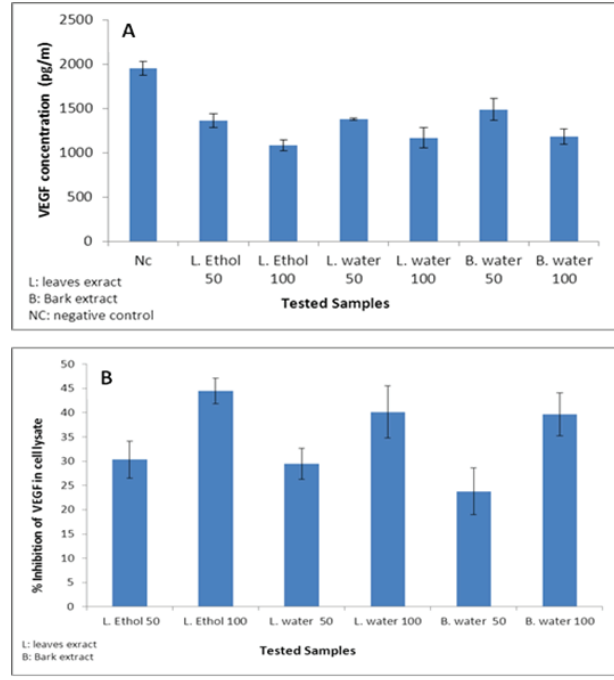

Figure $2 \mid$ (A)

Graphical representation of

VEGF level in

cells lysates of

endothelial cells

none treated and

treated with

different extracts

of A. leiocarpus

(B) VEGF inhibi-

tion in HUVECs

lysates by polar

and semi polar

extracts of $A$.

leiocarpus
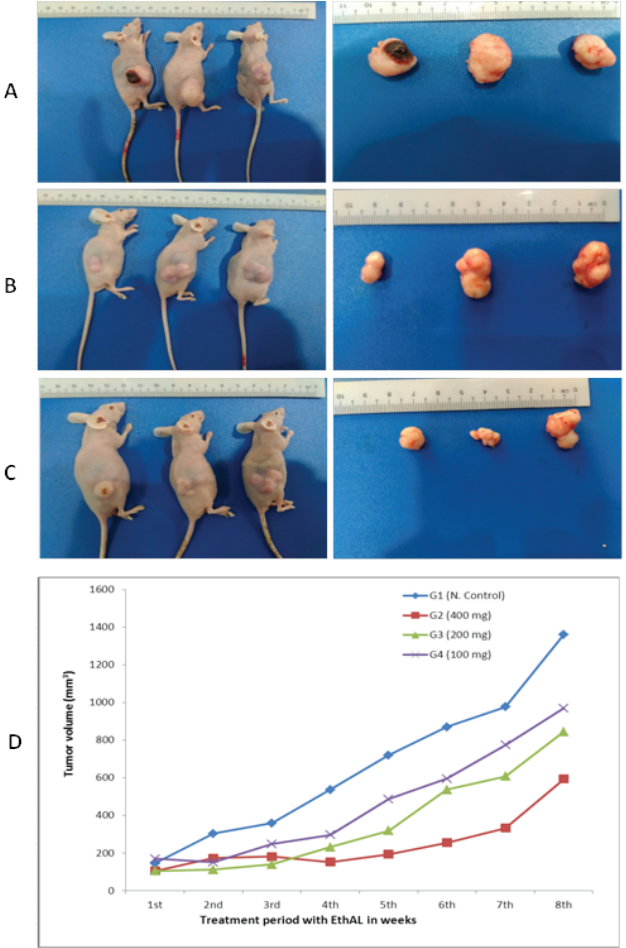

Figure 4 | In vivo antitumor activity evaluated in nude mice induced with HCT-116 tumor at four five weeks post-inoculation day. A) Untreated Animals; B) treated with $200 \mathrm{mg} / \mathrm{kg}$ A. leocarpus leaves ethanolic extract C) animals bearing tumors treated with $400 \mathrm{mg} / \mathrm{kg}$; D) Effect of leaves ethanolic on the average tumor growth. E) Effect EEL on animals' body weights. All values are expressed as mean \pm SD $(n=6)$. $P$ < $0.05,{ }^{* * P}<0.01$
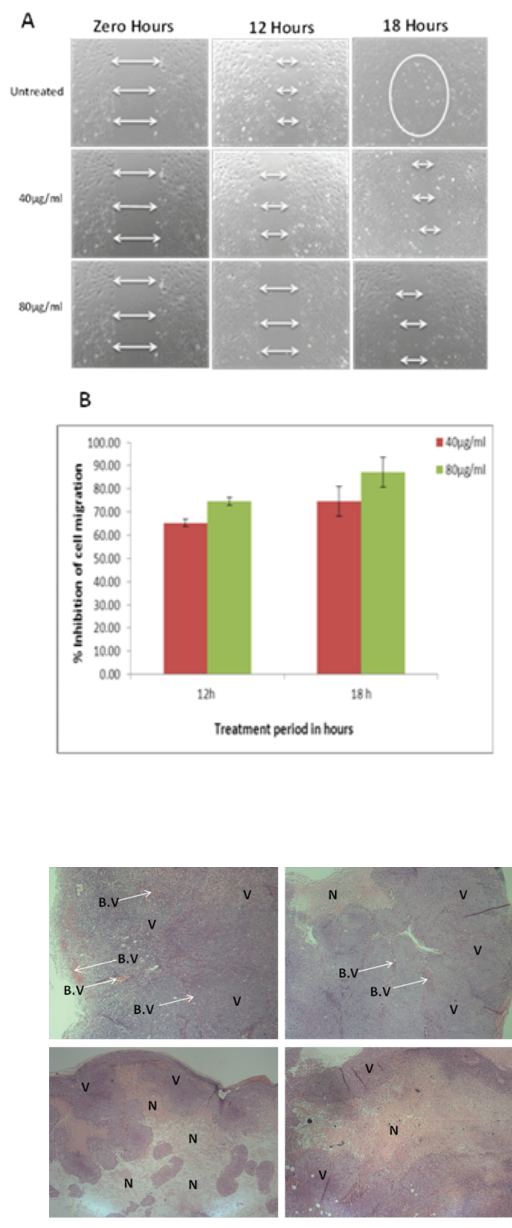

Figure 5| The tumor cross sections were stained with hematoxylin/eosin, and the number of the intratumor blood vessels was counted as well as extent of apoptosis/necrosis. A) Tumor tissue excised from untreated animals, the pictures were captured at $4 \times$ magnifications. The extents of the apoptotic/necrotic areas were less than in the treated groups. B) Tissue excised from animals treated with EEL $200 \mathrm{mg} / \mathrm{kg}$. C) Tumor specimen from animals treated with $400 \mathrm{mg} / \mathbf{k g}$. (B.V) refers to blood vessels, (V) refers to viable tumor cells, and (N) refers to necrotic/apoptotic tumor cells plastic activity of Anogeissus leiocarpus leaves ethanol extract (LEE) is could be attributed to antiangiogenic activity. The current study provides evidence for the first time that extracts of Anogeissus leiocarpus possess potent antiangiogenic, anti-tumor and antioxidant activities.

\section{Discussion}

Botanical extracts and their isolated phytochemical constituents are potential leads for developing antiangiogenic therapeutics due to their high antioxidant property beside phytochemical manifest it anti-angiogenic effect through multiple interdependent processes including singling process, gene expression and enzyme activities (Yance \& Sagar, 2006). The current study aimed to evaluate the antiangiogenic and antioxidant activities of Anogeissus leiocarpus as well as to assess its antitumor properties.
Six extracts obtained from the leaves and stem bark using three solvents, n-hexane was used to obtain the hydrophobic constituents whereas the intermediate hydrophobic and hydrophilic gained by ethanol and most hydrophilic obtained by water.

Tumors do not grow progressively beyond $2 \mathrm{~mm}^{3}$ in size and shed metastasis unless they acquire the capacity to induce blood supply from the surrounding stroma. Angiogenesis is a formation of new blood vessels from the pre-existing vasculature. Since angiogenesis initiation is crucial for cancer growth and metastasis, the anti-angiogenic therapy seems to be an important coadjuvant treatment against solid tumors. Moreover, after surgical resection of the malignancy, angiogenesis inhibition can help in avoiding cancer reappearance (Quail \& Joyce, 2013).

The angiogenesis signaling pathways form a complex, interconnected web. Inhibition of one pathway may result in compensation 
through another pathway. Plants contain a diverse organic compounds, that usually act on multiple targets. A potential advantage of phytochemicals is that they may act through multiple pathways to interrupt angiogenesis cascade and reduce development of resistance by cancer cells. This model of pharmacognosy recognizes the advantage of administering the whole botanical product to maximize efficacy. Over-fractionation and isolation of specific chemical constituents may eradicate this therapeutic advantage (Sagar et al., 2006). Emerging approach to improve efficacy and reduce site effects is to administered cytotoxic chemotherapy in combination with specific antiangiogenic agents. The present study is the first to provide evidence that leaves and stem bark of $A$. leiocarpus extracts possess potent antiangiogenic and anti-tumor activities.

Oxidative processes are an essential part of biochemical mechanisms such as cell respiration and other aspects of metabolism. Different types of free radical can be generated naturally in the organism; the most common types of possible physiological control are reactive oxygen species (ROS). Reactive oxygen species (ROS) as hydrogen peroxide $\left(\mathrm{H}_{2} \mathrm{O}_{2}\right)$ at low concentrations acts as signaling molecules in endothelial cells, however at elevated levels it can induce angiogenesis (Liou \& Storz, 2010). Normally, endothelial cells are maintained in a quiescent state, but under determined stimulus they can be activated in a process called "angiogenic switch". Among those angiogenic stimulatory factors are vascular endothelial growth factor (VEGF), angiopoetin-1 and 2, fibroblast growth factor basic (bFGF) and platelet-derived growth factor (PDGF). Reactive oxygen species (ROS) as hydrogen peroxide $\left(\mathrm{H}_{2} \mathrm{O}_{2}\right)$ participates in angiogenesis signaling through VEGF receptors, mainly VEGFR2 (Flk-1/KDR), and angiopoietin-I/Tie-2 receptors (Peter Carmeliet \& Jain, 2011; De Palma, Biziato, \& Petrova, 2017). In this study we aimed to evaluate the antioxidant activity of different extracts and to correlate it with antiangiogenic effects. Three methods were used to attain antioxidant activity (DPPH free radical scavenging, total phenolic and total flavonoids contents). The results showed that ethanol extract of the leaves and bark scored potent antioxidant activity with high phenolic and flavonoids consents. Noteworthily, extracts with high antioxidant activity exhibited significant antiangiogenic activity.

Several studies demonstrated that numerous antioxidants found in natural products (catechins from teas, resveratrol, polyphenols, flavonoids, isoflavones, lycopene, pigment epithelium derived factor, glutathione); nutritional components (vitamins $\mathrm{C}$, $\mathrm{D}, \mathrm{E}, \beta$-carotene and selenium); piruvate, pyrrolidine dithiocarbamate, and organoselenium compounds) were able to inhibit angiogenesis (Jiang, Agarwal, \& Lü, 2000; Samoylenko et al., 2013). Obviously, antioxidants have potential to interfere and downregulate tumor vasculature.
It has been indicated that regular consumption of polyphenols such as green tea and red wine associated with less occurrence of cancer and coronary heart disease (Vauzour et al, 2010). Previous studies demonstrated that polyphenolic compounds profoundly inhibit VEGF expression and $\mathrm{H}_{2} \mathrm{O}_{2}$-induced release of VEGF in vascular smooth muscle cells after administration of red wine (Oak, El Bedoui, \& Schini-Kerth, 2005). Also polyphenols exhibited ability to scavenge ROS such hydroxyl radical and superoxide anion (Upadhyay \& Dixit, 2015) and inevitably it curb the angiogenesis since ROS initiate neovascularization via induction of stimulatory angiogenic growth factors such as vascular endothelial growth factor (VEGF), angiopoetin-1 and 2, interleukin-8 (IL-8), fibroblast growth factor basic (bFGF), platelet-derived growth factor (PDGF) and angiotensin II (Murakami \& Simons, 2008; Veltmann et al., 2016). Epigallocatechin gallate (EGCG) a major polyphenol in green tea inhibited VEGF expression in many types of cancer cells by inhibiting epidermal growth factor receptor (EGF-R) (Chen et al., 2011).

Resveratrol is a polyphenolic compound found in grapes, juice grapes, red wine and other fruits. It has been reported to inhibit angiogenesis. It inhibited endothelial growth and proliferation induced by fibroblast growth factor-2 (FGF-2) and VEGF. The mechanisms underlying anti-angiogenic activity of resveratrol seem to depend on disruption of VEGF signaling and its antioxidant property. Polyphenols have key interference in a number of physiological events in angiogenesis, including those relating to oxidation reduction processes and interruption of major signaling pathways of neovascularization (Balasundram, Sundram, \& Samman, 2006). The results obtained from this study were in complete agreement with previous reports, the three most active extracts as antiangiogenic showed very high content of phenolic compounds, while hexane extract of the leaves with the lowest antiangiogenic effect showed lowest phenolic contents. The three extracts manifested their inhibition of neurovascular by inhibiting VEGF expression.

Flavonoids are chemical constitutes of plants that have a polyphenolic structure. It possesses strong anti-oxidative, anti-inflammatory and anti-septic and anticancer properties. Flavonoids and phenolics from plant source are reported to have various biological effects including antioxidant, anti-neovascularization, antiproliferation and anticarcinogenic properties and are therefore considered for their important dietary roles as chemoprotective agents (Galati \& O'Brien, 2004). The results showed that extracts with high content of flavonoids (water and ethanol extract of the leave, in addition to water extract of bark) prevented the formation new blood vessel formation from the rat aortic ring explants, whereas hexane extract of the bark scored the lowest contents of flavonoids and phenolic content. Nevertheless, it inhibited the formation of blood vessels from explant rat aorta; thus, its inhibi- 
tory effect could be attributed to its toxic nature.

Vascular outgrowth involves several steps such as endothelial cell proliferation and migration to get incorporated into the walls of growing vessels. Cell migration and invasion is an important step in tumor angiogenesis and metastasis and is considered to be an important target for cancer therapeutic (van Zijl, Krupitza, \& Mikulits, 2011).

Endothelial cells migrate into the surrounding tissue in response to angiogenic chemokines. Growth factors can enhance endothelial cell to migrate by causing random cell movement (chemokinesis) or directed migration toward a stimulatory factor (chemotaxis). The major chemotasis that drive cell migration during angiogenesis are Vascular Endothelial Growth factor (VEGF) and basic fibroblast growth factor (bFGF) in addition to activation of endothelial cells due to binding of integrins to extracellular matrix (ECM) (Ucuzian, Gassman, East, \& Greisler, 2010). Cell motility is of great interest in the design of anti-cancer therapeutics, as cell migration is required for both tumor invasion and tumor vasculature, moreover endothelial cells lack induced drug resistance and, therefore, antiangiogenic or angioprevention could be preferred strategy for cancer therapy in comparison to other treatments such as radiotherapy and chemotherapy (Eccles $\&$ Welch, 2007). Ethanol extract of the leaves which showed (high yield, potent antiangiogenic antioxidant activities) was evaluated for its effects on the main function of endothelial cells in angiogenesis cascade that's cell migration; it displayed profound inhibition of cell migration at none toxic doses.

Anti-angiogenic drugs may act by inhibiting synthesis of angiogenic proteins by neoplastic cells, neutralizing the angiogenic proteins, inhibiting the receptors of endothelia for angiogenic proteins, or directly inducing endothelial cell apoptosis. These inhibitors could be small molecules or specific antibodies that capable of targeting angiogenic growth factors, such as VEGF and bFGF, or angiogenic growth factor receptors, such as VEGFR and PDGFR (Gupta \& Qin, 2003).

VEGF plays a fundamental role in the neo-vascularization and vascular permeability. It's well known angiogenesis mediator in cancer and it's the main angiogenesis growth factor that initiate different steps in the angiogenesis cascade, such as endothelial proliferation, migration and differentiation (Gupta \& Qin, 2003). Thus, it is obvious that disruption of VEGF-signaling will result in the inhibition of angiogenesis process and pro-survival effects on the endothelial cells. Large number of phytochemicals has been shown to target tumor angiogenesis via inhibition of VEGF, for example Curcumin proofed to down-regulate transcript levels of VEGF and bFGF in estrogen receptor-negative breast cancer cell line MDA-MB-231 cells (Shao et al., 2002). Resveratrol, a grape polyphenol, suppresses tumor vasculature as well as tumor progression and metastasis. It also blocks capillary-like tube formation induced by VEGF as well as the binding of VEGF to the HUVEC (Seong et al., 2015). Other phytoconstituents such as EGCG, catechin-3-gallate, epicatechin-3-gallate, genistein and sesquiterpene lactone have been shown to hinder VEGF-induced tyrosine phosphorylation of VEGF receptor and inhibit angiogenesis process. To elucidate the mechanism by which the most active extracts prevented formation new blood vessels ethanol and water extracts of the leaves in addition to water extract of the bark were evaluated for their effect VEGF expression on HUVEC cells. The tree extract significantly inhibited the release of VEGF from endothelial cells in dose dependent manner. The results obtained in this work suggest that $A$. leiocarpus ethanol extract inhibited angiogenesis by curtailing secretion of the main angiogenesis growth factor (VEGF).

One of the central aims of the present study was to assess the antitumor efficacy (in vivo) of A. leiocarpus; we used a colon cancer xenograft model propagated in nude mice to determine whether the orally administered extract can curb tumor angiogenesis and tumor growth; by interacting with safety profile, antioxidant and preventing neoangiogenesis, for these reasons we tested the capacity of ethanol extract of A. leiocarpus leaves to inhibit colon cancer in vivo. The deficiency in $\mathrm{T}$ cell function allows athymic mice to accept and grow xenografts as well as allografts of normal and malignant tissues. Xenograft models of human tumors play an important role in the screening and evaluation of candidates for new antitumor agents. The results showed that the ethanol extract of the leaves inhibited the tumor growth in dose-dependent manner, Noteworthily, it prolonged the life span of animals bearing colon tumor treated with $400 \mathrm{mg} / \mathrm{kg}$ and $200 \mathrm{mg} / \mathrm{kg}$ at the end of eight weeks. The histological study of excised tumors showed fewer blood vessels in tumors and some signs of necrosis of treated groups when compared with negative group. The antitumor activity of $A$. leiocarpus leaves ethanolic extract could be attributed to its antiangiogenic activity.

\section{Conclusion}

The current investigation presents novel data to support the use of Anogeissus leiocarpus as a potential source of antitumor via angiogenesis pathway. Further studies including phytochemical studies to elucidate the active compounds and standardization of ethanol extract may be warranted to further support its potential value for cancer treatment and other angiogenesis related ailments.

\section{Acknowledgment}

The author would like to acknowledge the TWAS-USM (RF number: 32402401313) Scheme for the prestigious postgraduate funding, also author would like to thank Ministry of Higher Education, Sudan for financial support of this research work (Grant no.328/2017).

\section{Author Contribution}

LEAH performed all aspects of the project, he wrote the article, FSAS run in vivo study, SMFA help with in vitro tests and revise the layout, AMSA design and 
and supervise the work.

\section{Competing financial interests}

The author(s) declare no competing fnancial interests.

\section{References}

Ahmed Hassan, L. E., Khadeer Ahamed, M. B., Abdul Majid, A. S., Iqbal, M. A., Al Suede, F. S. R., Haque, Majid, A. M. S. A. (2014). Crystal Structure Elucidation and Anticancer Studies of (-)-Pseudosemiglabrin: A Flavanone Isolated from the Aerial Parts of Tephrosia apollinea. PLoS ONE, 9(3), e90806. doi: 10.1371/journal.pone.0090806

Albrecht, I., Kopfstein, L., Strittmatter, K., Schomber, T., Falkevall, A., Hagberg, C. E., ... Pietras, K. (2010). Suppressive effects of vascular endothelial growth factor-B on tumor growth in a mouse model of pancreatic neuroendocrine tumorigenesis. PloS one, 5(11), e14109. Retrieved from https://doi.org/10.1371/journal.pone.0014109 doi:10.1371/journal.pone.0014109

Baghel, S., Shrivastava, N., RS Baghel, P., \& Rajput, S. (2012). A review of quercetin: antioxidant and anticancer properties. World J Pharm Pharmaceutical Sci, 1(1), 146 160.

Balasundram, N., Sundram, K., \& Samman, S. (2006). Phenolic compounds in plants and agri-industrial by-products: antioxidant activity, occurrence, and potential uses. Food Chem, 99(1), 191 - 203.

Blacher, S., Devy, L., Noel, A., \& Foidart, J.-M. (2011). QUANTIFICATION OF ANGIOGENESIS ON THE RAT AORTIC RING ASSAY. [angiogenesis; complexity; fibroblast-like cells; microvessels; quantification]. 2011, 22(1), 6. doi: 10.5566/ias.v22.p43-48

Carmeliet, P. (2005). Angiogenesis in life, disease and medicine. Nature, 438(7070), 932-936. doi: 10.1038/nature04478

Carmeliet, P., \& Jain, R. K. (2011). Molecular mechanisms and clinical applications of angiogenesis. Nature, 473(7347), 298-307. doi: 10.1038/nature10144

Chen, D., Wan, S. B., Yang, H., Yuan, J., Chan, T. H., \& Dou, Q. P. (2011). EGCG, GREEN TEA POLYPHENOLS AND THEIR SYNTHETIC ANALOGS AND PRODRUGS FOR HUMAN CANCER PREVENTION AND TREATMENT. Advances in Clinical Chemistry, 53, 155-177.

Chirinos, R., Pedreschi, R., Rogez, H., Larondelle, Y., \& Campos, D. (2013). Phenolic compound contents and antioxidant activity in plants with nutritional and/or medicinal properties from the Peruvian Andean region. Industrial Crops and Products, 47(Supplement C), 145-152. doi: https://doi.org/10.1016/j.indcrop.2013.02.025

Corbett, T., Polin, L., LoRusso, P., Valeriote, F., Panchapor, C., Pugh, S., .. J Jones, J. (2004). In vivo methods for screening and preclinical testing Anticancer drug development guide (pp. 99-123): Springer.

De Flora, S., \& Ferguson, L. R. (2005). Overview of mechanisms of cancer chemopreventive agents. Mutation Research/Fundamental and Molecular Mechanisms of Mutagenesis, 591(1-2), 8-15. doi: https://doi.org/10.1016/j.mrfmmm.2005.02.029

De Palma, M., Biziato, D., \& Petrova, T. V. (2017). Microenvironmental regulation of tumour angiogenesis. Nat Rev Cancer, 17(8), 457-474. doi: 10.1038/nrc.2017.51

Eccles, S. A., \& Welch, D. R. (2007). Metastasis: recent discoveries and novel treatment strategies. Lancet, 369(9574), 1742-1757. doi: 10.1016/S0140-6736(07)60781-8

Folkman, J., \& Klagsbrun, M. (1987). Angiogenic factors. Science, 235(4787), $442-447$.

Galati, G., \& O'Brien, P. (2004). Potential toxicity of flavonoids and other dietary phenolics: significance for their chemopreventive and anticancer properties. Free Radic Biol Med, 37(3), 287 - 303.

Gupta, M. K., \& Qin, R.-Y. (2003). Mechanism and its regulation of tumor-induced angiogenesis. World Journal of Gastroenterology : WJG, 9(6), 1144-1155. doi: 10.3748/wjg.v9.i6.1144

Hassan, L. E., Ahamed, M. B., Majid, A. S., Baharetha, H. M., Muslim, N. S., Nassar, Z. D., \& Majid, A. M. (2014). Correlation of antiangiogenic, antioxidant and cytotoxic activities of some Sudanese medicinal plants with phenolic and flavonoid contents. BMC Complement Altern Med, 14, 406. doi: 10.1186/1472-6882-14-406

Hassan, L. E. A., Dahham, S. S., Saghir, S. A. M., Mohammed, A. M. A., Eltayeb, N. M., Majid, A. M. S. A., \& Majid, A. S. A. (2016). Chemotherapeutic potentials of the stem bark of Balanite aegyptiaca (L.) Delile: an antiangiogenic, antitumor and antioxidant agent. BMC Complementary and Alternative Medicine, 16, 396. doi: 10.1186/s12906-016-1369-5

Hassan, L. E. A., Iqbal, M. A., Dahham, S. S., Tabana, Y. M., Ahamed, M. B. K., \& Majid, A. (2017). Colorectal, Prostate and Pancreas Human Cancers Targeted Bioassay-guided Isolations and Characterization of Chemical Constituents from Tephrosia apollinea. Anticancer Agents Med Chem, 17(4), 590-598. doi: $10.2174 / 1871520616666160926113711$

Hennenberg, K. J., Goetze, D., Minden, V., Traoré, D., \& Porembski, S. (2005). Size-class distribution of Anogeissus leiocarpus (Combretaceae) along forest-savanna ecotones in northern Ivory Coast. Journal of Tropical Ecology, 21(3), 273-281. doi: $10.1017 /$ S0266467404002160

Jiang, C., Agarwal, R., \& Lü, J. (2000). Anti-Angiogenic Potential of a Cancer Chemopreventive Flavonoid Antioxidant, Silymarin: Inhibition of Key Attributes of Vascular Endothelial Cells and Angiogenic Cytokine Secretion by Cancer Epithelial Cells. Biochemical and Biophysical Research Communications, 276(1), 371-378. doi: https://doi.org/10.1006/bbrc.2000.3474

Kim, Y.-W., West, X. Z., \& Byzova, T. V. (2013). Inflammation and oxidative stress in angiogenesis and vascular disease. [journal article]. Journal of Molecular Medicine, 91(3), 323-328. doi: 10.1007/s00109-013-1007-3

Konaté, K., Kiendrébéogo, M., Ouattara, M. B., Souza, A., Lamien-Meda, A., Nongasida, Y., ... Nacoulma, O. G. (2011). Antibacterial Potential of Aqueous Acetone Extracts from Five Medicinal Plants used Traditionally to Treat Infectious Diseases in Burkina Faso. Current Research Journal of Biological Sciences, 3(5), 435-442.

Kumamoto, M., Nakashima, Y., \& Sueishi, K. (1995). Intimal neovascularization in human coronary atherosclerosis: Its origin and pathophysiological significance. Human Pathology, 26(4), 450-456. doi: https://doi.org/10.1016/0046-8177(95)90148-5

Liang, C.-C., Park, A. Y., \& Guan, J.-L. (2007). In vitro scratch assay: a convenient and inexpensive method for analysis of cell migration in vitro. Nature protocols, 2(2), 329-333.

Liou, G.-Y., \& Storz, P. (2010). Reactive oxygen species in cancer. Free radical research, 44(5), 10.3109/10715761003667554. doi: 10.3109/10715761003667554

Luna, L. G., \& Armed Forces Institute of, P. (1968). Manual of histologic staining methods of the Armed Forces Institute of Pathology. New York: Blakiston Division, McGraw-Hill.

Mammen, D., \& Daniel, M. (2012). A critical evaluation on the reliability of two aluminum chloride chelation methods for quantification of flavonoids. Food Chemistry, 135(3), 1365-1368. doi: https://doi.org/10.1016/j.foodchem.2012.05.109 
Mosmann, T. (1983). Rapid colorimetric assay for cellular growth and survival: application to proliferation and cytotoxicity assays. J Immunol Methods, 65(1-2), 55-63. Murakami, M., \& Simons, M. (2008). Fibroblast growth factor regulation of neovascu larization. Current opinion in hematology, 15(3), 215-220. doi: 10.1097/MOH.0b013e3282f97d98

Oak, M. H., El Bedoui, J., \& Schini-Kerth, V. B. (2005). Antiangiogenic properties of natural polyphenols from red wine and green tea. J Nutr Biochem, 16(1), 1-8. doi: 10.1016/j.jnutbio.2004.09.004

Okpekon, T., Yolou, S., Gleye, C., Roblot, F., Loiseau, P., Bories, C., ... Hocquemiller, R. (2004). Antiparasitic activities of medicinal plants used in Ivory Coast. Journal of Ethnopharmacology, 90(1), 91-97. doi: https://doi.org/10.1016/j.jep.2003.09.029 Ottu, O. J., Atawodi, S. E., \& Onyike, E. (2013). Antioxidant, hepatoprotective and hypolipidemic effects of methanolic root extract of Cassia singueana in rats following acute and chronic carbon tetrachloride intoxication. Asian Pacific Journal of Tropical Medicine, 6(8), 609-615. doi: https://doi.org/10.1016/S1995-7645(13)60105-4 Papiewska-Pająk, I., Balcerczyk, A., Stec-Martyna, E., Koziołkiewicz, W., \& Boncela,

J. (2017). Vascular endothelial growth factor-D modulates oxidant-antioxidant balance of human vascular endothelial cells. Journal of Cellular and Molecular Medicine, 21(6), 1139-1149. doi: 10.1111/jcmm. 13045

Phaniendra, A., Jestadi, D. B., \& Periyasamy, L. (2015). Free Radicals: Properties, Sources, Targets, and Their Implication in Various Diseases. Indian Journal of Clinical Biochemistry, 30(1), 11-26. doi: 10.1007/s12291-014-0446-0

Quail, D. F., \& Joyce, J. A. (2013). Microenvironmental regulation of tumor progression and metastasis. Nature medicine, 19(11), 1423-1437. doi: 10.1038/nm.3394

Rini, B. I., \& Small, E. J. (2005). Biology and Clinical Development of Vascular Endothelial Growth Factor-Targeted Therapy in Renal Cell Carcinoma. Journal of Clinical Oncology, 23(5), 1028-1043. doi: 10.1200/jco.2005.01.186

Russell, W., \& Duthie, G. (2011). Plant secondary metabolites and gut health: the case for phenolic acids. Proceedings of the Nutrition Society, 70(3), 389-396. doi: 10.1017/S0029665111000152

Sagar, S. M., Yance, D., \& Wong, R. K. (2006). Natural health products that inhibit angiogenesis: a potential source for investigational new agents to treat cancer-Part 1 . Current Oncology, 13(1), 14-26.

Saggar, J. K., Yu, M., Tan, Q., \& Tannock, I. F. (2013). The Tumor Microenvironment and Strategies to Improve Drug Distribution. Frontiers in Oncology, 3, 154. doi: 10.3389/fonc. 2013.00154

Samoylenko, A., Hossain, J. A., Mennerich, D., Kellokumpu, S., Hiltunen, J. K., \& Kietzmann, T. (2013). Nutritional Countermeasures Targeting Reactive Oxygen Species in Cancer: From Mechanisms to Biomarkers and Clinical Evidence. Antioxidants \& Redox Signaling, 19(17), 2157-2196. doi: 10.1089/ars.2012.4662

Seong, H., Ryu, J., Jeong, J. Y., Chung, I. Y., Han, Y. S., Hwang, S. H., ... Seo, S. W. (2015). Resveratrol suppresses vascular endothelial growth factor secretion via inhibition of CXC-chemokine receptor 4 expression in ARPE-19 cells. Mol Med Rep,

12(1), 1479-1484. doi: 10.3892/mmr.2015.3518

Shahidi, F., \& Naczk, M. (1995). Food phenolics : sources, chemistry, effects, applications. Lancaster, Pa.: Technomic Pub. Co.

Shao, Z. M., Shen, Z. Z., Liu, C. H., Sartippour, M. R., Go, V. L., Heber, D., \& Nguyen, M. (2002). Curcumin exerts multiple suppressive effects on human breast carcinoma cells. Int J Cancer, 98(2), 234-240.

Sharma, O. P., \& Bhat, T. K. (2009). DPPH antioxidant assay revisited. Food Chemistry, 113(4), 1202-1205. doi: https://doi.org/10.1016/j.foodchem.2008.08.008

Singh, D., Baghel, U. S., Gautam, A., Baghel, D. S., Yadav, D., Malik, J., \& Yadav, R. (2016). The genus Anogeissus: A review on ethnopharmacology, phytochemistry and pharmacology. Journal of Ethnopharmacology, 194(Supplement C), 30-56. doi: https://doi.org/10.1016/j.jep.2016.08.025
Staton, C. A., Stribbling, S. M., Tazzyman, S., Hughes, R., Brown, N. J., \& Lewis, C. E. (2004). Current methods for assaying angiogenesis in vitro and in vivo. International Journal of Experimental Pathology, 85(5), 233-248. doi: 10.1111/j.0959-9673.2004.00396.x

Subbaraju, G., \& Trimurtulu, G. (2004). History of Natural Supplements in Cancer Therapy and Prevention Phytopharmaceuticals in Cancer Chemoprevention: CRC Press. Theresa Ibibia, E., Oghenerobor Benjamin, A., \& Stephen Olugbemiga, O. (2016). Determination of antibacterial activity, total phenolic, flavonoid and saponin contents in leaves of Anogeissus leiocarpus (DC.) Guill and Perr. Journal of Coastal Life Medicine, 4(4), 310-314. doi: 10.12980/jclm.4.2016J5-218

Therond, P. (2006). [Oxidative stress and damages to biomolecules (lipids, proteins, DNA)]. Ann Pharm Fr, 64(6), 383-389.

Tomayko, M. M., \& Reynolds, C. P. (1989). Determination of subcutaneous tumor size in athymic (nude) mice. Cancer chemotherapy and pharmacology, 24(3), 148-154.

Ucuzian, A. A., Gassman, A. A., East, A. T., \& Greisler, H. P. (2010). Molecular Mediators of Angiogenesis. Journal of burn care \& research : official publication of the American Burn Association, 31(1), 158. doi: 10.1097/BCR.0b013e3181c7ed82 Upadhyay, S., \& Dixit, M. (2015). Role of Polyphenols and Other Phytochemicals on Molecular Signaling. Oxidative Medicine and Cellular Longevity, 2015, 15. doi: $10.1155 / 2015 / 504253$

Van Zijl, F., Krupitza, G., \& Mikulits, W. (2011). Initial steps of metastasis: Cell invasion and endothelial transmigration. Mutation Research, 728(1-2), 23-34. doi: 10.1016/j.mrrev.2011.05.002

Vauzour, D., Rodriguez-Mateos, A., Corona, G., Oruna-Concha, M. J., \& Spencer, J. P. E. (2010). Polyphenols and Human Health: Prevention of Disease and Mechanisms of Action. Nutrients, 2(11), 1106-1131. doi: 10.3390/nu2111106 Veltmann, M., Hollborn, M., Reichenbach, A., Wiedemann, P., Kohen, L., \& Bringmann, A. (2016). Osmotic Induction of Angiogenic Growth Factor Expression in Human Retinal Pigment Epithelial Cells. PLoS ONE, 11(1), e0147312. doi: 10.1371/journal.pone.0147312

Walter, A., Etienne-Selloum, N., Brasse, D., Schleiffer, R., Bekaert, V., Vanhoutte, P., ... Schini-Kerth, V. (2009). Red wine polyphenols prevent acceleration of neovascularization by angiotensin II in the ischemic rat hindlimb. J Pharmacol Exp Ther, 329(no. 2), $329-699$

Yance, D. R., \& Sagar, S. M. (2006). Targeting Angiogenesis With Integrative Cancer Therapies. Integrative Cancer Therapies, 5(1), 9-29. doi: 10.1177/1534735405285562

Submit your next manuscript to Angiotherpay published by EMAN Research.

- Convenient online submission

- Thorough peer review

- No space constraints or color figure charges

- Immediate publication on acceptance

- Inclusion in Australian National Libraray and Google Scholar

- Both Open (80-100\% subsidized APC by ER) \& non-open access option

Submit your manuscript at

angiotherapy.emanresearch.org eman Research 